\title{
Effectiveness of combined preventive methods on erupting teeth in children in a fluoridated community
}

\author{
Robert A. Bagramian*, Sujan Srivastava* and Righard C. Graves** \\ *Department of Community Dentistry, School of Dentistry, University of Michigan, \\ Ann Arbor, Michigan, **School of Dentistry, University of Tennessee, Memphis, Tennessee, \\ U.S.A.
}

\begin{abstract}
Bagramian, R. A., Srivastava, S. \& Graves, R. C.: Effectiveness of combined preventive methods on erupting teeth in children in a fluoridated community. Community Dent. Oral Epidemiol. 1979: 7: 246-251.

Abstract - Several preventive methods were used in combination to reduce dental caries in children residing in a fluoridated area. The methods included dental health education, prophylaxis, pit and fissure sealants, topical fluoride and restorative care. Prophylaxis, sealant and fluoride procedures were repeated every 6 months. Sealant was applied to all fully erupted caries free posterior teeth in the mouth. This report compares results obtained for teeth that erupted after the study began with those teeth that were already present at the time treatment procedures were applied. Percent reductions in caries increment for newly erupted teeth at the end of 3 years for treated 6th graders was $77.5 \%$ in DMFT and $79.2 \%$ DMFS as compared to $71 \%$ and $58.3 \%$ for previously erupted teeth. Results for children in 1st grade did not show such beneficial results. Permanent first molars in younger children appear to be highly susceptible to caries. Sealant retention for newly erupted teeth follows the same pattern as for teeth previously erupted.
\end{abstract}

Key words: dental caries; fissure sealants; fluorides; teeth, eruption.

R. A. Bagramian, Department of Community Dentistry, University of Michigan School of Dentistry, Ann Arbor, Michigan 48109, U.S.A.

Accepted for publication 27 May 1979.

Many studies have dealt with sealant applications on occlusal surfaces of teeth with differing results. In general, sealants seem to be effective in reducing caries on occlusal surfaces of teeth to a considerable degree $(7,10,11)$. The teeth under study in most cases were those already present in the mouth and exposed to the attack of dental caries. However, the rapid onset of occlusal caries in newly erupted primary and permanent teeth as documented by HeNNON and co-workers (8) and Dirks (6) indicates the need for early preventive treatment.

HenNon et al. (8), in a study of caries activity in preschool children ages $1-3$, found that approximately one-third of children examined already had dental decay. Dirks (6) reported on a sample of boys and girls in the Netherlands in which nearly all occlusal surfaces in permanent first molars had decayed by age 9 , and in permanent second molars by age 14 .

Evidence from a study by Stephen et al. (14) shows that in a 6-month interval between an initial examination and when sealants were placed, $20 \%$ of molars which were initially caries free had developed deep lesions. Lewis \& Hargreaves (9) have shown that $80 \%$ of erupted permanent first molars in a group of 7-year-old children were carious and that a reduction of $36 \%$ to $42 \%$ would be possible if occlusal sealing was not delayed beyond this age. Risager \& Poulsen (13) were also of a similar opinion. 
This study was designed so that combined preventive methods were applied both to caries-free teeth present in the mouth at the time of initiation of the study, as well as to 'erupting' teeth or teeth that erupted into the mouth as the study progressed. Previous reports of the study have presented findings on (a) effectiveness of sealant combined with other treatment procedures in caries prevention and (b) retention patterns of sealant at the end of 1 (1), 2 (2), and 3 years (3) for teeth which had fully erupted and present at the start of the study. In this report, results on the effectiveness of combined treatment procedures applied to teeth that erupted into the mouth after the study was initiated will be presented. We will arbitrarily call these teeth 'erupting'.

It should be noted, however, that sealant was applied to an 'erupting' tooth only when it had fully erupted into the mouth after its entire occlusal surface had penetrated the gingival tissue. In other words, sealant was applied for the first time 6 months, a year or 18 months after initial eruption had begun. As for sealant retention, figures presented in this report are for those teeth which had sealant applied 1 year after initiation of the program. This period was chosen since it was noted that maximum number of permanent molars, permanent first molars in younger and permanent second molars in older children, had erupted fully at that point in time.

\section{METHODS}

The population under study comprised 1200 schoolchildren living in low to low-middle socioeconomic areas of a high- ly populated city of Southeastern Michigan. Approximately $30 \%$ of the children were non-white.

The project was initiated in February, 1973. The children enrolled in the project were from 1st and 6th grades of 18 schools in the school districts of Ypsilanti and Willow Run. These children were randomly assigned to two groups of equal size, a treatment group and an education group.

Rationale for selection of 1 st and 6th grade children was that at these ages children have a large number of permanent teeth, first molars in 1st graders and second molars and premolars in 6th graders, erupting into the mouth. It was believed that benefits from occlusal sealing could be enhanced if application were done soon after eruption of the teeth, thereby giving immediate protection from the caries attack in the oral environment.

Treatment group children received the following combination of five preventive and therapeutic procedures: 1 . The ingestion of optimally fluoridated drinking water (city water has been fluoridated since 1964 with 1.0 part $/ 10^{6}$ of fluoride). 2. Dietary counseling and an oral hygiene education program in classrooms, including supervised toothbrushing and flossing, aided by disclosing tablets for 32 wecks in the year. 3. Dental examinations, prophylaxis and the application of Bis-GMA pit and fissure sealants (Nuva Seal ${ }^{\circledR}$ Buonocore method every 6 months) to the occlusal surfaces of all sound teeth as well as to those that had lost sealant. 4. Topical application of acidulated phosphate fluoride gel $(1.23 \%)$ in a tray for 4 minutes every 6 months. 5. The provision of all necessary restorative care semiannually.

Children in the comparison group also consumed fluoridated water, and were also provided oral hygiene education in the classroom.

Annual assessments of the oral health of the treatment and education group children were conducted by two examiners carefully trained and calibrated in epidemiologic methods. Examination methods were highly standardized. Criteria used to assess dental caries were those developed at the 1968 ADA Conference on the clinical testing of cariostatic agents (15). Blindness of the exami-

Table 1. Three-year DMFT and DMFS increment for erupting teeth in 1st grade children, Ypsilanti, Michigan, 1973-76

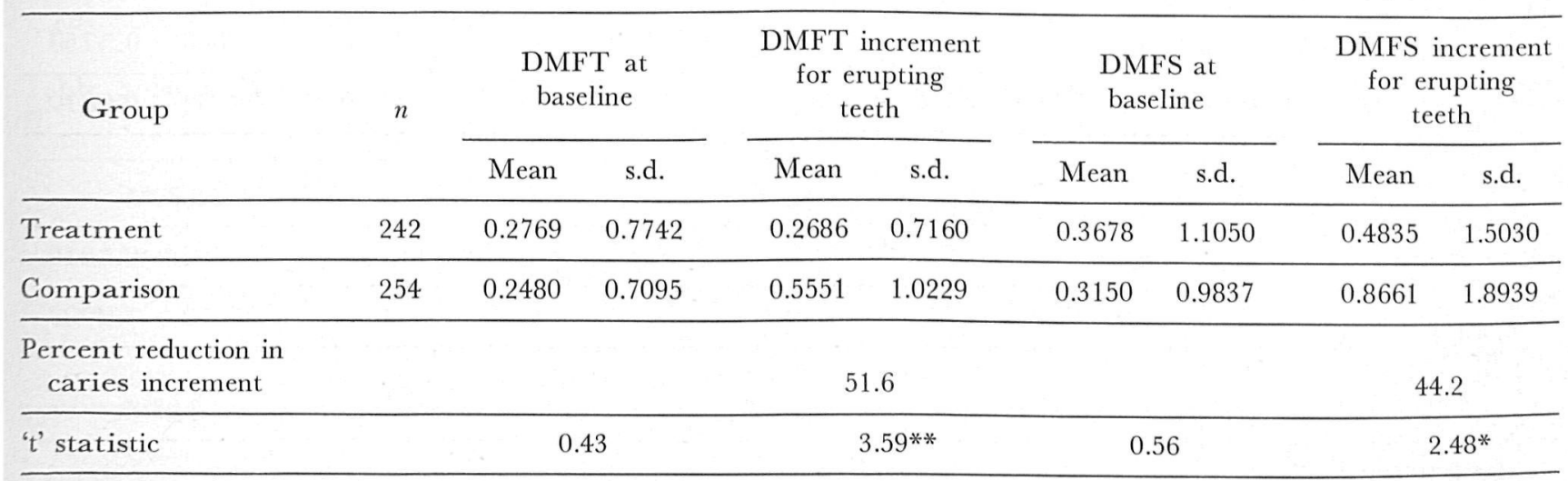

* Significant at $P<0.01$. ${ }^{*}$ Significant at $P<0.05$. 
Table 2. Three-year DMFT and DMFS increment for erupting teeth in 6th grade children, Ypsilanti, Michigan $1973-76$

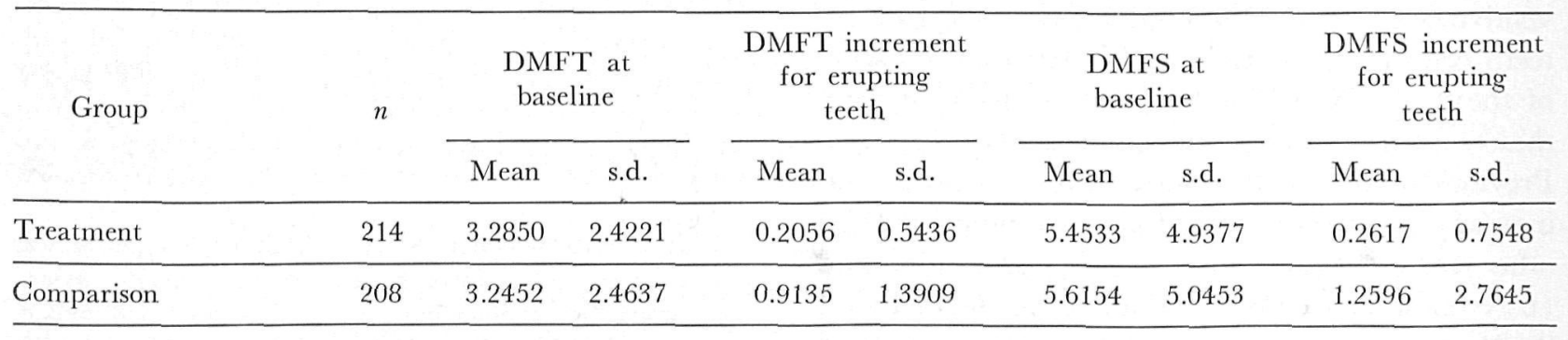

Percent reduction in caries increment

\begin{tabular}{llll}
\hline 't' statistic 0.17 & $6.92^{* *}$ & 0.33 & $5.09^{* * *}$ \\
\hline
\end{tabular}

** Significant at $P<0.01$.

ners was maintained during the study as much as possible. During the examination process, previous examination records were not available to examiners.

Posterior bite-wing radiographs were taken annually for all children and are used for caries assessments as well as clinical treatment. Radiographs were interpreted and charted on a separate form by a dentist who was not an examiner, without benefit of results from the clinical examination. Radiographic findings were then added to clinical data.

Sealant condition was assessed by the same clinical examiners at 6-month intervals. With the aid of mirror and explorer, the occlusal surfaces of teeth were examined visually and tactilely for the presence of sealant. If no sealant could be detected, the sealant was considered completely lost; if all pits and fissures were covered, the sealant was considered completely retained; all other possibilities ranging from a small amount of sealant detectable to nearly all present was classified as partially retained.

Details of the study design and scoring methods are contained in previous reports on this study $(1,2)$.

\section{RESULTS}

Tables 1-3 pertain solely to teeth erupted into the mouth since initiation of the project. Their numbers for 1st graders in treatment and education groups were 2056 and 2218 respectively. Corresponding figures for 6th graders were 992 and 903 respectively.

Table 3. Three-year DMFS increment by surface type for erupting teeth in 1st and 6th grade children, Ypsilanti, Michigan $1973-76$

\begin{tabular}{|c|c|c|c|c|c|c|c|c|}
\hline \multirow[t]{2}{*}{ Grade } & \multirow[t]{2}{*}{ Group } & \multirow[t]{2}{*}{$n$} & \multicolumn{2}{|c|}{$\begin{array}{c}\text { Buccolingual } \\
\text { increment }\end{array}$} & \multicolumn{2}{|c|}{$\begin{array}{c}\text { Mesiodistal } \\
\text { increment }\end{array}$} & \multicolumn{2}{|c|}{$\begin{array}{l}\text { Occlusal } \\
\text { increment }\end{array}$} \\
\hline & & & Mean & s.d. & Mean & s.d. & Mean & s.d. \\
\hline \multirow{2}{*}{ First } & Treatment & 242 & 0.1736 & 0.6464 & 0.1033 & 0.5170 & 0.2066 & 0.5750 \\
\hline & Comparison & 254 & 0.2953 & 0.8218 & 0.0827 & 0.4758 & 0.4882 & 0.9810 \\
\hline \multirow{2}{*}{ Sixth } & Treatment & 214 & 0.0701 & 0.3490 & 0.0280 & 0.1655 & 0.1636 & 0.4810 \\
\hline & Comparison & 208 & 0.2404 & 1.1547 & 0.1635 & 1.0911 & 0.8558 & 1.2997 \\
\hline
\end{tabular}

* Significant at $P<0.05$.

* Significant at $P<0.01$. 
Sixty-seven percent of the total number of teeth that erupted in 1st graders in both groups during the 3-year-period were central and lateral incisors and canines, while at the same time caries incidence in these tooth types was nil. Most caries occurred in permanent first molars which accounted for only $13 \%$ of teeth that erupted and is the most susceptible tooth type at that age. At least $72 \%$ of first graders had one or more permanent first molars already erupted at the time of enrollment in the project. More than $80 \%$ of teeth that erupted in 6 th graders during the 3-year-period were permanent second molars and premolars. Permanent second molars in 6th graders accounted for almost all caries experienced by these older children. Of the few anterior teeth that erupted in this age group, none experienced caries. Hence, DMFT and DMFS figures given in the Tables are for the relevant posterior teeth mentioned above.

The number of permanent first molars that erupted in 1st graders by the end of 3 years from the start of the program was 556 compared with 803 permanent second molars that erupted in 6th graders.

Tables 1 and 2 give DMFT and DMFS figures for 'erupting' teeth or teeth that erupted into the mouth during the 3 -year-period since the project began, in 1st and 6th grade children. The tables indicate a twofold increment in DMFT for the comparison group compared with the treatment group in 1st grade children and a fourfold increment in 6 th grade children. The corresponding reductions in DMFT increment for the two grades were $51.6 \%$ and $77.5 \%$, respectively. Differences in DMFT increment between the two groups in both grades were statistically significant at $P<0.01$. Percentage
Table 4. Percent reductions* in 3rd year DMFT and DMFS increments for erupting and previously erupted teeth in 1st and 6th grade children, Ypsilanti, Michigan, 1973-76

\begin{tabular}{|c|c|c|c|c|c|}
\hline \multirow[t]{2}{*}{ Grade } & \multirow[t]{2}{*}{ Examination } & \multicolumn{2}{|c|}{$\begin{array}{l}\text { Erupting } \\
\text { teeth }\end{array}$} & \multicolumn{2}{|c|}{$\begin{array}{c}\text { Previously } \\
\text { erupted } \\
\text { teeth }\end{array}$} \\
\hline & & DMFT & DMFS & DMFT & DMFS \\
\hline First & $\begin{array}{l}\text { Baseline } \\
\text { vs. 3rd year }\end{array}$ & 51.6 & 44.2 & 65.6 & 66.7 \\
\hline Sixth & $\begin{array}{l}\text { Baseline } \\
\text { vs. 3rd year }\end{array}$ & 77.5 & 79.2 & 71.0 & 58.3 \\
\hline
\end{tabular}

$\frac{* \text { Difference in caries increment between groups }}{\text { Caries increment in comparison group }} \times 100$.

reductions in DMFS increment for the two grades were $44.2 \%$ and $79.2 \%$ respectively. Caries appears to have occurred soon after initial eruption even before the teeth were exposed to treatment, particularly with permanent first molars.

Table 3 gives 3 -year DMFS increment by surface type for 'erupting' teeth in children from both grades and groups. As with previously erupted teeth, difference in occlusal caries increments between the two groups was found to be highly significant both for older as well as for younger children.

Results on percent reductions in caries increment among 6th graders at the end of 3 years for 'erupting' teeth are very encouraging compared to previously erupted teeth (Table 4). Percent reductions in DMFT and DMFS at the end of 3 years in the present study for 'erupting' teeth among 6th graders were $77.5 \%$ and $79.2 \%$ respectively. It was 71.0 and $58.3 \%$, respectively, for teeth previously

Table 5. Sealant status at the end of 2 years for erupting teeth in 1st and 6th grade children, Ypsilanti, Michigan, 197376

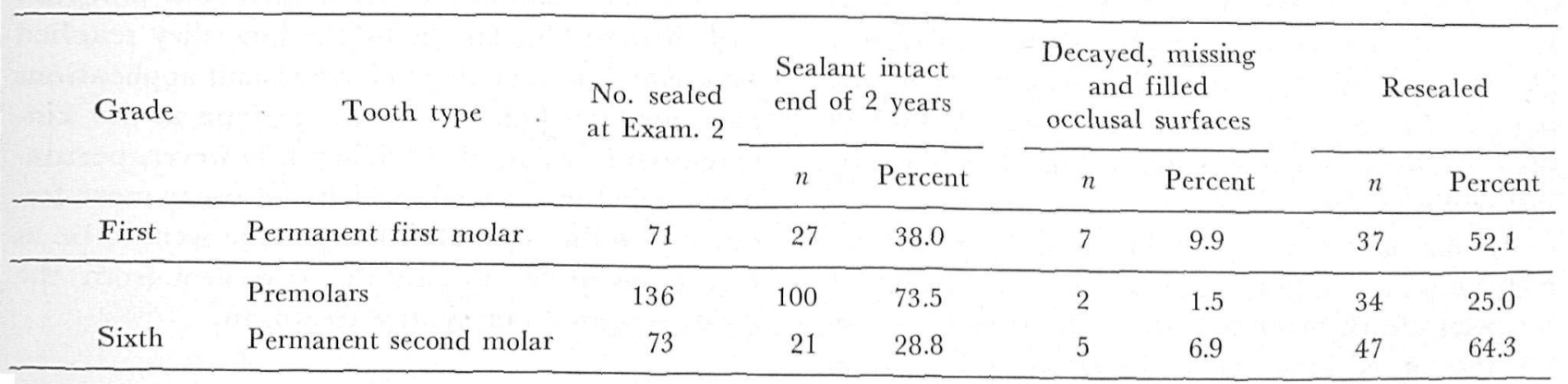


erupted. For 1st graders, however, percent reductions in DMFT and DMFS increment for 'erupting' teeth did not compare as well with previously erupted teeth. Treatment procedures seem to be more beneficial to 'erupting' teeth in older children.

Another aspect of the study is sealant retention. Table 5 gives sealant retention figures after 2 years for permanent first molars in younger children and premolars and permanent second molars in older children, respectively.

Nearly $58 \%$ of all teeth that were sealed in older children retained sealant at the end of 2 years, whereas it was $38 \%$ for the younger children. From the Table it is evident that retention figures are best, $73.5 \%$ for premolars in 6th grade children. Retention in permanent first molars of 1 st graders and in permanent second molars of 6th graders was low, $38.0 \%$ and $28.8 \%$, respectively. These figures follow the same pattern as those for previously erupted teeth (2). Further, the caries rate has been extremely low, particularly for premolars. Although retention rates do not seem high for the most posterior teeth in the mouth, viz. permanent second molars in 6th graders and permanent first molars in 1st graders, the large percentage that were resealed and the low caries rates show the effectiveness of reapplications of sealant in preventing caries.

\section{DISGUSSION}

Success of this study was assessed by caries reduction. Differences in DMFT and DMFS increments between treatment and comparison groups at the end of 3 years for both 1 st and 6th graders were statistically significant.

Although the number of 'erupting' permanent second molars in 6th grade children were nearly $1 \mathrm{I} / 2$ times as many as permanent first molars in 1 st grade children, nearly twice as many of the latter teeth became carious as compared to the former. Hence, it seems that permanent first molars are highly susceptible to caries. At the same time, the position in the mouth and tooth morphology of these teeth make sealant application and retention rather difficult.

Results on percentage reduction in caries increment among 6th graders at the end of 3 years for 'erupting' teeth are impressive. The percentage reduction in occlusal caries increment of 80.2 at the end of 2 years, is comparable with that of Ripa, Buonocore \& Cueto (12) who reported an $85.6 \%$ reduction in occlusal caries activity at the end of 2 years in newly erupted premolars and molars.

In this study, emphasis was placed on caries prevention rather than sealant retention. Since sealants were reapplied every 6 months, teeth which were questionable as having sealant intact were, in many instances, resealed. The total number of erupting teeth that were sealed was less than that reported by Cons et al. (5). Also, the teeth selected in the present study did not have a matching complete cariesfree pair.

BuRt et al. (4) found sealant intact in $38.1 \%$ of maxillary first molars and in $39.9 \%$ of mandibular first molars at the end of 6 months. Of the 205 children who participated in the study, almost $70 \%$ of them were aged between 5 and 8 years and $72 \%$ of the 427 pairs of teeth that were sealed were permanent first molars. The study was carried out under normal school dental service conditions and examinations were carried out 'blind'.

One reason for differences in sealant retention figures could be the age at which sealant is applied. Comparisons between studies are difficult unless the ages of study participants are comparable. Sealant application technique also appears to be strongly related to retention of sealant.

Treatment procedures are highly beneficial for 'erupting' teeth in older children. Permanent first molars in younger children appear to be highly susceptible to caries. Since most caries in permanent first molar teeth occurs on the occlusal surface, sealant application should be done immediately after eruption. In the present study there is a time lag of 1-6 months before a new fully erupted tooth has its first sealant application, which suggests that sealant applications may have to be done within the first 3 months after full eruption for younger children. Since a large number of children in this program had their first molars in by the time they reached 1st grade, it is advisable to have sealant applications done for these children earlier, perhaps at the kindergarten level. In older children, however, permanent second molar teeth, which also decay most frequently on the occlusal surface, do not seem to be as highly susceptible to caries as is evident from the good response to preventive treatment. 
Acknowledgment - This study was supported by Grant No. NIH-NIDR-72-2410 from the National Institute for Dental Research, National Institutes of Health, Bethesda, Maryland.

\section{REFERENGES}

1. Bagramian, R. A., Graves, R. C. \& Bhat, M.: A combined approach to preventing dental caries in school children: caries reduction after one year. I. Am. Dent. Assoc. 1976: 93: 1014-1019.

2. Bagramian, R. A., Graves, R. C. \& Srivastava, S.: Sealant effectiveness for children receiving a combination of preventive methods in a fluoridated community: two-year results. J. Dent. Res. 1977: 56: 1511-1519.

3. Bagramian, R. A., Graves, R. G. \& Srivastava, S.: A combined approach to preventing dental caries in schoolchildren: caries reduction after 3 years. Community Dent. Oral Epidemiol. 1978: 6: 166-171.

4. Burt, B. A., Berman, D. S., Gellier, S. \& SilversTone, L. M.: Retention of a fissure sealant six months after application. Br. Dent. J. 1975: 138: 98-100.

5. Cons, N. C., Pollard, S. T. \& Leske, G. S.: Results of a three-year study in a fluoridated area. J. Prev. Dent. 1976: 3: 14-18.

6. Dirks, O. B.: Longitudinal dental caries study in children 9-15 years of age. Arch. Oral Biol. 1961: 6: Suppl.: 94-108.

7. Douglas, W. H. \& Tranter, T. C.: Do fissure sea- lants really work? (Abstr.) J. Dent. Res. Spec. Issue D 1976: 45: 117.

8. Hennon, D. K., Stookey, G. K. \& Muhler, J. G.: Prevalence and distribution of dental caries in preschool children. J. Am. Dent. Assoc. 1969: 79: 14051414.

9. Lewis, D. W. \& Hargreaves, J. A.: Epidemiology of dental caries in relation to pits and fissures. Br. Dent. J. 1975: 138: 345-348.

10. Murray, J. J. \& Williams, B.: Fissure sealants and dental caries: a review. J. Dent. 1975: 3: 145-152.

11. RipA, L. W.: The current status of occlusal sealants. $J$. Prev. Dent. 1976: 3: 6-14.

12. Ripa, L. W., Buonocore, M. \& Cueto, E.: Adhesive sealant of pits and fissures for caries prevention: Report of two year study. (Abstr.) IADR Program and Abstract of Papers 1966: 44: 247.

13. Risager, J. \& Poulsen, S.: Fissure sealing with NuvaSeal in a public health program for Danish school children after 12 months observation. Scand. J. Dent. Res. 1974: 82: 570-573.

14. Stephen, K. W., Sutherland, D. A. \& Trainer, J.: Fissure sealing by practitioners - First year retention data in Scottish 6 year old children. Br. Dent. J. 1976: 140: 45-51.

15. American Dental Association, Council on Dental Research and Council on Dental Therapeutics: Principles for the clinical testing of cariostatic agents. American Dental Association, Chicago 1972. 
This document is a scanned copy of a printed document. No warranty is given about the accuracy of the copy. Users should refer to the original published version of the material. 